\title{
Simulation and Analysis of Power-point Tracking via Photovoltaic Sensors
}

\author{
Fujian Zhang, ${ }^{1}$ Weidong Ye, ${ }^{1 *}$ Guoping Lei, ${ }^{2}$ \\ Yingying Liu, ${ }^{1}$ Xian Wang, ${ }^{1}$ and Chao $\mathrm{He}^{3 * *}$ \\ ${ }^{1}$ College of International Vocational Education, Shanghai Polytechnic University, Shanghai 201209, China \\ ${ }^{2}$ School of Electronics and Information Engineering, Chongqing Three Gorges University, \\ Chongqing 404130, China \\ ${ }^{3}$ School of Communication and Information Engineering, \\ Chongqing University of Posts and Telecommunications, Chongqing 400065, China
}

(Received July 1, 2021; accepted October 4, 2021)

Keywords: PV cells, radiation intensity, output characteristics, maximum power point tracking, output power

The photovoltaic (PV) cell is the basic component of a solar power system as it converts light energy into electricity by the PV effect. To increase the efficiency of conversion, the maximum power point (MPP) of the battery must be tracked in real time. We have established a system model based on the main characteristics of the PV power generation system and PV cells that considers the nonlinearity of the PV cell output. The mathematical model of a PV array is established by MATLAB/Simulink and combined with the common equivalent circuit of a PV cell and the mathematical model of PV power generation. This model enables the maximum power point tracking (MPPT) control of the PV cell through the simulation of its current-voltage $(I-V)$ characteristic curve, which shows the cell's operation within its electrical circuit. We propose a MPPT control algorithm based on this model as an improved perturbation observation method. This algorithm controls the working current of the inverter of the PV cell using a PV sensor. Changes in light intensity or working temperature do not affect the ability of the tracking system to reliably track the MPP. This method does not need complex analysis and the control is based on a simple principle. Simulation results show that the algorithm has good dynamic performance in a steady state. The proposed method can track the MPP and improve the PV power generation efficiency by reflecting changes in illumination intensity with time.

\section{Introduction}

The progress of science and technology and the improvement of people's living standards require more energy than before, which can no longer be satisfied with traditional fossil fuel power generation. Therefore, the large-scale development and utilization of new forms of energy are necessary to protect the environment and achieve sustainable development. The depletion and environmental problems of fossil fuels have led to the development of renewable energy sources. Among the sources, photovoltaic (PV) power (solar power) generation has attracted

\footnotetext{
*Corresponding author: e-mail: wdye@sspu.edu.cn

** Corresponding author: e-mail: d170101004@stu.cqupt.edu.cn

https://doi.org/10.18494/SAM.2021.3520
} 
much research interest as it is easier to install solar power plants and obtain energy with much fewer geographical limitations on the plants than for other renewable energy sources. Therefore, large-scale PV power plants have been developed rapidly and have become increasingly popular. This has contributed to the rapid development of PV cells as the essential component of these systems. However, the output of PV power generation systems is significantly affected by light intensity and temperature, which does not allow stable power generation.

To solve this problem by improving the efficiency of systems, the maximum power point tracking (MPPT) method has been proposed. The principle of MPPT is to maximize the energy transfer from PV cells, which depends on the incidence angle of sunlight, the temperature of the PV cell, and the electrical properties of the system, by using various sensing technologies. To collect the maximum power from a PV power generation system using MPPT, several components, such as a sliding mode controller (SMC), a voltage source inverter (VSI) and grid design, and a PV generator (PVG) are required. ${ }^{(1)}$ These are integrated into the system to display its motion trajectory with the inverter topology that is used in an algorithm to optimize the maximum power point (MPP).

The module for motion trajectory includes a calendar chip that calculates the current position and height of the sun using the current time and local latitude and longitude. The microcontroller drives motors to move the PV panels to receive the maximum incidence of sunlight. ${ }^{(2)}$ The PV array and inverter are important for improving the power conversion rate in MPPT because decreasing the number of electronic devices and having a compact structure will enable simple control, low power consumption, and, accordingly, high conversion efficiency. ${ }^{(3)}$ This is related to the algorithm that controls the system efficiently. Previous research on algorithms for MPPT mainly adopted the MATLAB/Simulink platform. ${ }^{(4)}$ The hill-climbing algorithm was proposed for boosting circuit operation and achieving effective MPPT, ${ }^{(5)}$ which is regarded as simple and effective. This method combines simplified particle swarm optimization and the step-size perturbation observation method to ensure a fast, simple, and efficient process with limited hardware resources.

In this study, we propose a new design of a view-based motion trajectory system and a mathematical model for improving the efficiency of the PV automatic tracking system. The system replaces the traditional trajectory system with the view-based system. The new model provides optimal and stable PV arrays and an accurate simulation of the PV power generation system that improves the power generation and decreases the current loss due to the transmission between components of the PV power generation system.

\section{Methods}

\subsection{Basic principle of MPPT}

MPPT is a dynamic and self-optimizing process that matches the internal resistance of the PV battery. Its function is the real-time detection of the voltage of the power generated by the PV panel to monitor the peak voltage and current of the PV power generation system. The high voltage allows the high efficiency of the battery pack, which is the purpose of using MPPT. ${ }^{(6,7)}$ 
The factory-set peak voltage $\left(V_{p p}\right)$ and ambient reference temperature of a solar panel are about $17 \mathrm{~V}$ and $25^{\circ} \mathrm{C}$ in general, respectively. Under ideal conditions, the charge and discharge efficiencies of the solar controller increase by about $50 \%$ with MPPT. ${ }^{(8)}$ Recent MPPT algorithms adopt various methods such as fixed voltage, disturbance observation, incremental conductivity, and fuzzy logic control methods. ${ }^{(9)}$ Figure 1 shows a schematic diagram of an MPPT system that includes a PV module, a DC-DC converter circuit, and a pulse-width modulation control circuit.

\subsection{Control algorithm}

The disturbance observation method is often applied to the control of MPPT to improve the system power oscillation near the MPP of a PV battery by reducing the perturbation step size. ${ }^{(10)}$ This method is not efficient in maintaining a balance between tracking speed and obtained power so it has limited applications. When the step size is large, the tracking speed increases, and operating points vary greatly near the MPP, which results in a large loss of output power but accurate tracking. ${ }^{(11)}$ If the step size is small, the range of operating points decreases near the MPP, resulting in a small power loss and an increased number of disturbances. This increases the tracking time, ${ }^{(12)}$ and the power-voltage $(P-U)$ characteristic curve satisfies $\Delta P / \Delta U=0$ near the MPP. To simplify the calculation, $\Delta P / \Delta U$ is replaced with a certain voltage increment. ${ }^{(13)}$

When the duty cycle decreases, $U$ increases by $\Delta U$ to $U_{1}\left(U_{1}=U+\Delta U\right)$.

(1) When $P_{k}>P_{k-1}$, the operation mode is located on the left side of the MPP and the disturbance direction remains unchanged.

(2) When $P_{k}<P_{k-1}$, the operation mode is located on the right side of the MPP and the disturbance direction changes.

When the duty cycle increases, $U$ decreases by $\Delta U$ to $U_{1}\left(U_{1}=U-\Delta U\right)$.

(1) When $P_{k}>P_{k-1}$, the operation mode is located on the right side of the MPP and the disturbance direction remains unchanged.

(2) When $P_{k}<P_{k-1}$, the operation mode is located on the left side of the MPP and the disturbance direction changes.

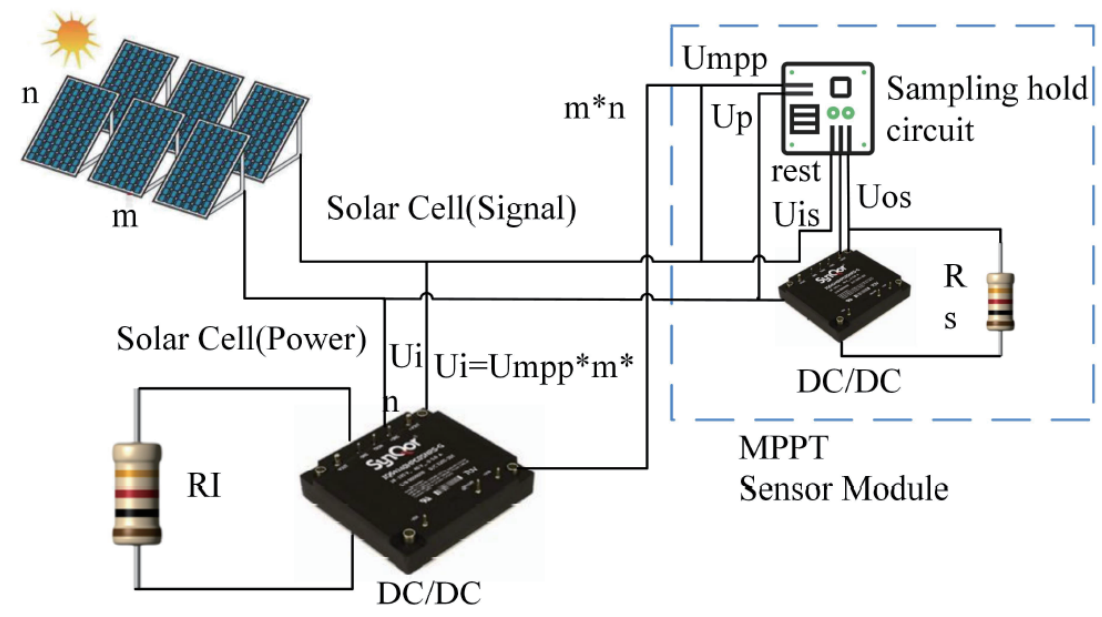

Fig. 1. (Color) Schematic diagram of MPPT system. 


\subsection{Mathematical model}

A solar PV power generation system transforms solar energy into electric energy through the PV effect of solar cells and stores the energy in the battery. Since the battery is connected to the load at both ends, current flows through the load to produce output power as shown in Fig. 2.

Figure 3 shows a circuit of the battery of the PV power generation system. According to Kirchhoff's current law and Kirchhoff's voltage law, the mathematical model of current and voltage is defined as ${ }^{(5)}$

$$
I_{L}=I_{p h}-I_{D}-I_{S h}
$$

When $R_{S}$ is small and $R_{s h}$ is large, they have a negligible effect on the output of the battery. Therefore, in the analysis of the actual circuit, $R_{S}$ or $R_{s h}$ can be ignored.(5) When $R_{s h}$ of the equivalent circuit in Fig. 3 reaches several thousand ohms, its effect on the circuit can also be neglected. Thereby, the circuit model is simplified to that shown in Fig. 4, and the output characteristic is expressed as

$$
I_{L}=I_{p h}-I_{D}\left[\exp \left(\frac{q\left(V_{O C}+I_{L} R_{S}\right)}{A K T}\right)-1\right]
$$

According to Eq. (2), the output voltage and current for the battery are affected by light intensity and temperature, which have a linear relationship with $I_{p h} \cdot{ }^{(5)}$ The relationship between light intensity and temperature is defined as

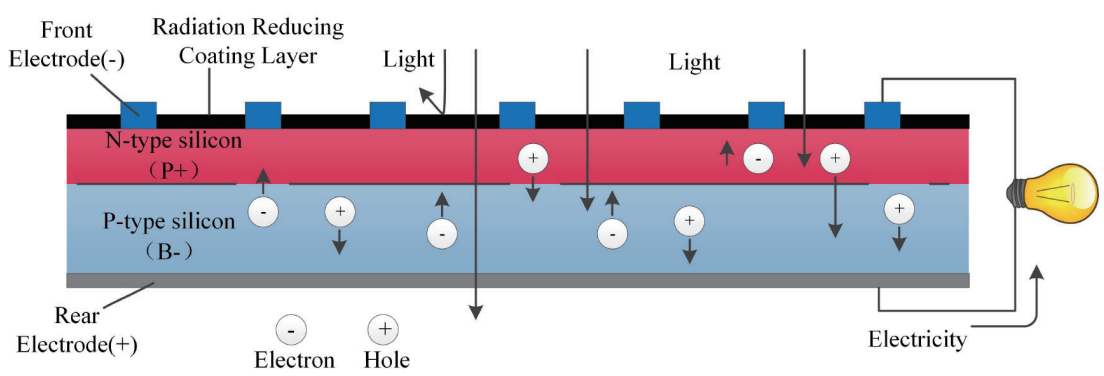

Fig. 2. (Color) Schematic diagram of a PV cell.

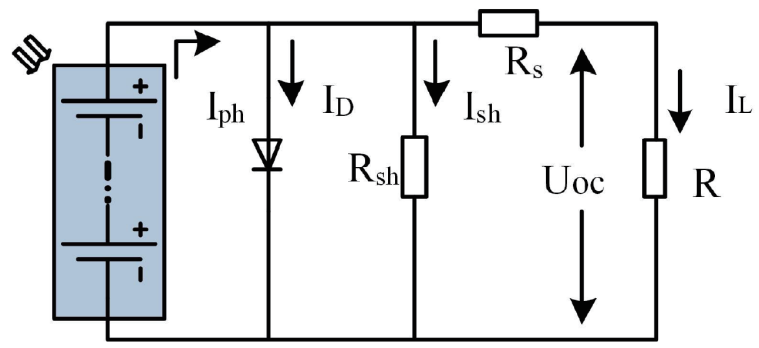

Fig. 3. (Color) Circuit model of the battery of the PV power generation system. 


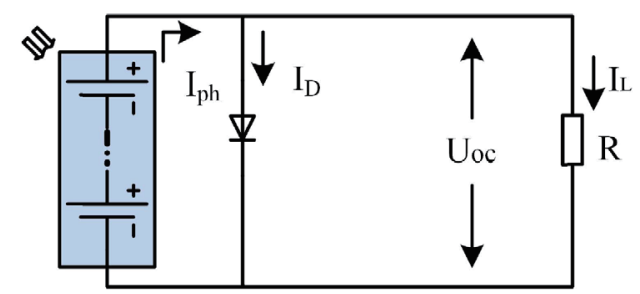

Fig. 4. (Color online) Simplified circuit model of the battery of the PV power generation system.

$$
U_{O C}=\frac{A K T}{q} \ln \left(\frac{I_{p h}}{I_{D}}+1\right),
$$

where $A K T$ is the temperature coefficient of the open-circuit voltage and $U_{O C}$ is the open-circuit voltage for the benchmark test (light intensity $G=1000 \mathrm{~W} / \mathrm{m}^{2}$ and temperature $=25^{\circ} \mathrm{C}$ ). $(14)$

\section{Results and Discussion}

\subsection{Parameters of simulation}

A MATLAB/Simulink simulation of the battery of the PV power generation system based on the above equations was established. The parameters of the battery are shown in Table 1.

The output characteristics of the voltage and current of the battery are determined by ambient temperature $(T)$ and light intensity $(G)$. The model of the battery was simulated by using different values of $\mathrm{G}$ and $\mathrm{T}$, whose standard values were $1000 \mathrm{~W} / \mathrm{m}^{2}$ and $25^{\circ} \mathrm{C}$, respectively. By setting $G=1000 \mathrm{~W} / \mathrm{m}^{2}$, T values of $5,15,25,30$, and $40{ }^{\circ} \mathrm{C}$ were used to obtain the simulated values of the parameters. The obtained results are shown in Table 2.

The simulated values of the parameters were calculated with $T=25^{\circ} \mathrm{C}$ and $G=200,400$, 600,800 , and $1000 \mathrm{~W} / \mathrm{m}^{2}$. The obtained results are shown in Table 3.

Table 1

Parameters of battery of PV power generation system used in simulation.

\begin{tabular}{lc}
\hline Parameter & Value \\
\hline$V_{O C}$ & $21.6 \mathrm{~V}$ \\
$V_{m}$ & $17.2 \mathrm{~V}$ \\
$I_{S C}$ & $3.41 \mathrm{~A}$ \\
$I_{m}$ & $3.19 \mathrm{~A}$ \\
$\alpha$ & 0.015 \\
$\beta$ & -0.07 \\
$R$ & $2 \Omega$ \\
\hline
\end{tabular}

Table 2

Simulated values of parameters obtained by model with $G$ fixed at $1000 \mathrm{~W} / \mathrm{m}^{2}$.

\begin{tabular}{cccll}
\hline$T\left({ }^{\circ} \mathrm{C}\right)$ & $V_{O C}(\mathrm{~V})$ & $V_{m}(\mathrm{~V})$ & $I_{S C}(\mathrm{~A})$ & $I_{m}(\mathrm{~A})$ \\
\hline 5 & 35.6 & 31.2 & 3.11 & 2.89 \\
15 & 28.6 & 24.2 & 3.26 & 3.04 \\
25 & 21.6 & 17.2 & 3.41 & 3.19 \\
30 & 18.1 & 13.7 & 3.335 & 3.265 \\
40 & 11.1 & 6.7 & 3.185 & 3.415 \\
\hline
\end{tabular}


Table 3

Simulated values of parameters obtained by model with $T$ fixed at $25^{\circ} \mathrm{C}$.

\begin{tabular}{cllll}
\hline$G\left(\mathrm{~W} / \mathrm{m}^{2}\right)$ & $V_{O C}(\mathrm{~V})$ & $V_{m}(\mathrm{~V})$ & $I_{S C}(\mathrm{~A})$ & $I_{m}(\mathrm{~A})$ \\
\hline 200 & 21.6 & 17.2 & 0.638 & 0.682 \\
400 & 21.6 & 17.2 & 1.364 & 1.276 \\
600 & 21.6 & 17.2 & 2.046 & 1.914 \\
800 & 21.6 & 17.2 & 2.728 & 2.552 \\
1000 & 21.6 & 17.2 & 3.41 & 3.19 \\
\hline
\end{tabular}

\subsection{Simulation results}

\subsection{1 $V-I$ and $P-U$ relationships}

The simulated results were plotted as $V-I$ and $P-U$ curves for different values of sunlight intensity and temperature. Figures 5 and 6 show the simulation results of $I-V$ and $P-U$ curves at $T=25^{\circ} \mathrm{C}$ with $G$ values of $200,400,600,800$, and $1000 \mathrm{~W} / \mathrm{m}^{2} .{ }^{(15)}$ With the solar radiation intensity $(G)$ fixed at $1000 \mathrm{~W} / \mathrm{m}^{2}$, the ambient temperature was lowered from 40 to $5^{\circ} \mathrm{C}$. It was



(a)

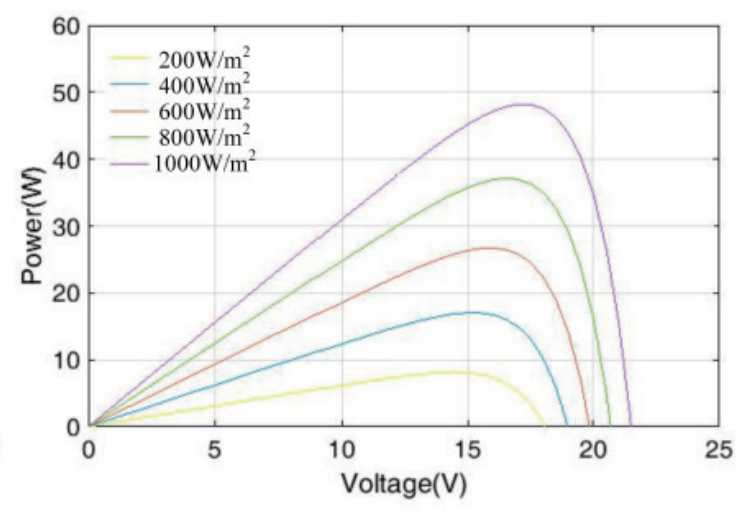

(b)

Fig. 5. $\quad I-V$ and $P-U$ curves of simulated PV power regulation system at $T=25^{\circ} \mathrm{C}$ and different light intensities.

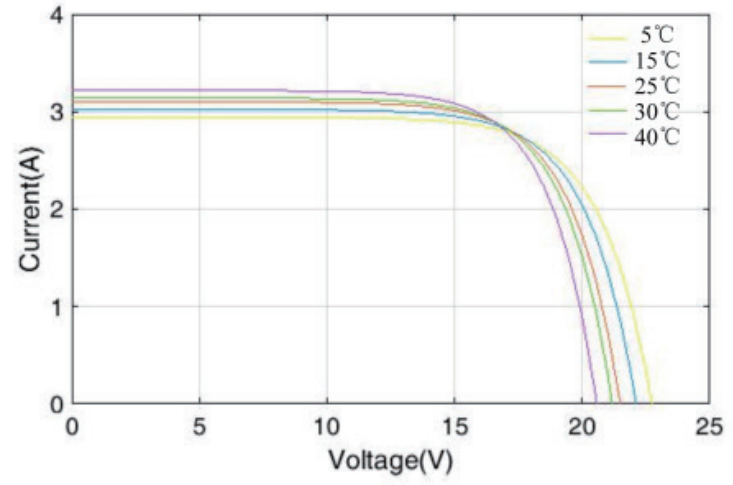

(a)

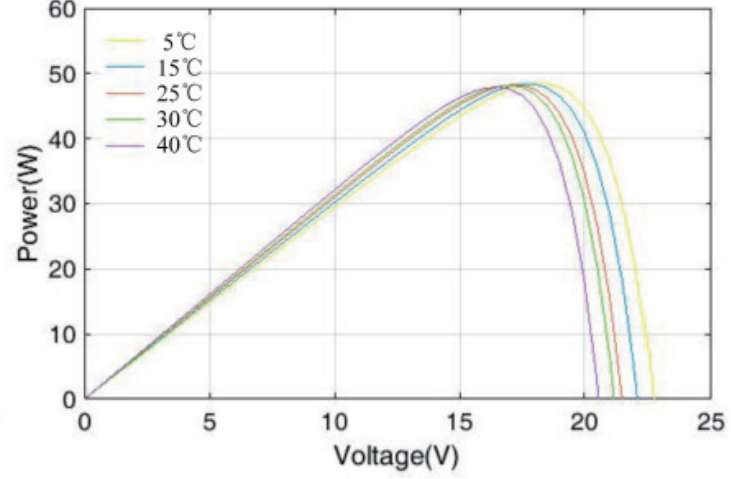

(b)

Fig. 6. $\quad V-I$ and $P-V$ curves of simulated PV power regulation system at $G=1000 \mathrm{~W} / \mathrm{m}^{2}$ and different temperatures. 
found that the maximum power and optimal working voltage of the system gradually increased with decreasing temperature. Also, with the ambient temperature $(T)$ fixed at $25{ }^{\circ} \mathrm{C}$, the solar radiation intensity was reduced from 1000 to $200 \mathrm{~W} / \mathrm{m}^{2}$.

The optimal working voltage remained unchanged, but the maximum power gradually decreased. As the PV array is highly susceptible to external factors, the operating voltage and that of the system have a nonlinear relationship. Therefore, it is important to make the system have one MPP with varying light intensity or temperature, which maximizes the efficiency of the PV power generation system.

\subsubsection{Simulation results}

The simulation model of the disturbance observation method was established by MATLAB/ Simulink by using the parameters in Table 2. In addition to the parameters, a sampling time of 5 $\times 10^{-5} \mathrm{~s}$, a switching frequency of $2 \times 10^{3}$, a disturbance compensation length of $0.001 \mathrm{~mm}$, and an initial duty cycle of 0.5 were input to the simulation model. The simulated results are shown in Figs. 7 and 8.

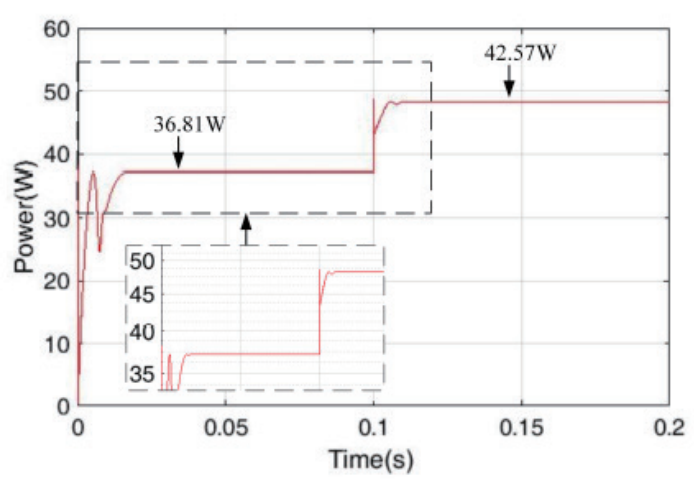

(a)

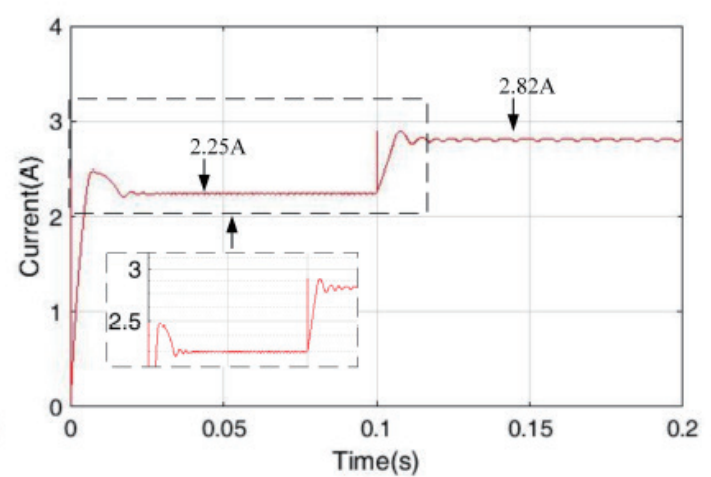

(b)



(c)

Fig. 7. (Color online) $P-V$ curve when $G=1000 \mathrm{~W} / \mathrm{m}^{2}$ and $T=25^{\circ} \mathrm{C}$. (a) MPP, (b) $I_{m}$, and (c) $V_{m}$ tracking diagrams. 


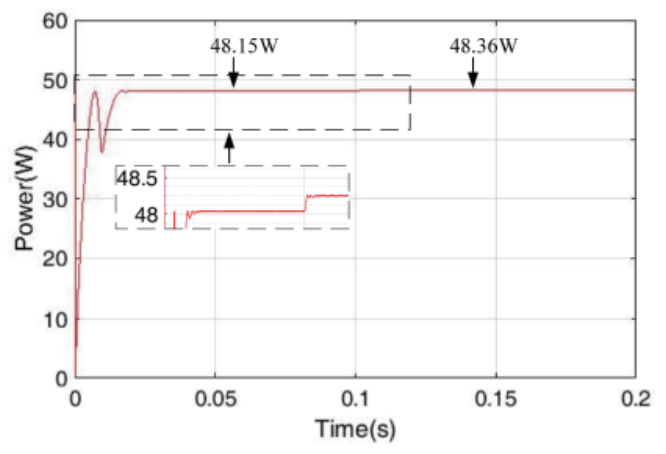

(a)

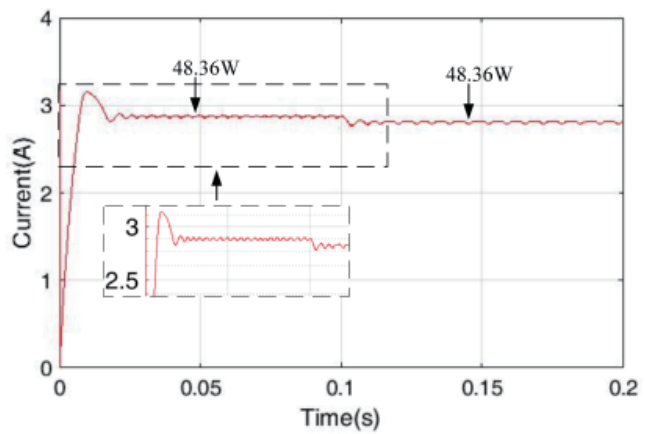

(b)



(c)

Fig. 8. (Color online) $P-V$ curve when $G=800 \mathrm{~W} / \mathrm{m}^{2}$ and $T=15^{\circ} \mathrm{C}$ (until $0.1 \mathrm{~s}$ ), and $G=1000 \mathrm{~W} / \mathrm{m}^{2}$ and $T=25^{\circ} \mathrm{C}$ (up to $0.2 \mathrm{~s}$ ). (a) MPP, (b) $I_{m}$, and (c) $V_{m}$ tracking diagrams.

Figure 7 shows that the system reached the MPP in less than $0.01 \mathrm{~s}$ for $G=1000 \mathrm{~W} / \mathrm{m}^{2}$ and $T$ $=25{ }^{\circ} \mathrm{C}$. The maximum power achieved by the disturbance observation method was $55.1 \mathrm{~W}$ with a fluctuation of $1.8 \mathrm{~W}$, which we regard as ideal for the MPP tracking system. The power first reached a peak and fluctuated until a stable MPP value of $55 \mathrm{~W}$ was maintained after $4 \mathrm{~ms}$.

For $G=800 \mathrm{~W} / \mathrm{m}^{2}$ and $T=15{ }^{\circ} \mathrm{C}$, the power fluctuated considerably and reached a stable value of $42 \mathrm{~W}$. Then, $G$ and $T$ were changed to $1000 \mathrm{~W} / \mathrm{m}^{2}$ and $25^{\circ} \mathrm{C}$, respectively, which contributed to the sudden increase in power to $55 \mathrm{~W}$ from $0.1 \mathrm{~s}$ (Fig. 8).

Figure 9 shows that the power fluctuated and reached a stable value of $30 \mathrm{~W}$ at $0.1 \mathrm{~s}$ for $G=600 \mathrm{~W} / \mathrm{m}^{2}$ and $T=30^{\circ} \mathrm{C}$. The power suddenly dropped to less than $10 \mathrm{~W}$, then increased to $20 \mathrm{~W}$ when $\mathrm{G}$ and $\mathrm{T}$ were changed to $600 \mathrm{~W} / \mathrm{m}^{2}$ and $30^{\circ} \mathrm{C}$, respectively.

Both step-change modes can track the MPP and the output voltage and current of the PV battery within about $0.01 \mathrm{~s}$. The parameters (light intensity $G$ and temperature $T$ ) of the system change at $0.1 \mathrm{~s}$, which occurs in about $1 \mathrm{~ms}$. Once again, by tracking the MPP and reaching a steady state, the dynamic characteristics and stability of the system can reflect changes in light intensity in a timely and smooth manner, and the system can quickly trace the maximum power output of the PV battery. ${ }^{(16)}$ 


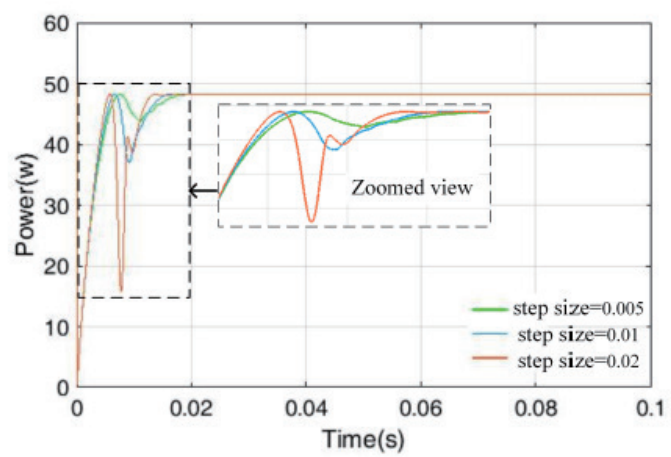

(a)



(b)

Fig. 9. (Color online) (a) Simulation comparison of the MPPT in different step sizes. (b) Simulation comparison of the Convention P\&O and Proposed MPPT.

\section{Conclusions}

To determine the characteristics of the MPP of a PV power generation system, we established and simulated a model using MATLAB/Simulink. The MPPT of a PV battery was obtained by an improved disturbance observation method. Simulation results revealed that the system model found the MPP efficiently, which effectively improved the output efficiency of the PV system. This method requires only a small part of the PV cell body to be used as the PV sensor to monitor its electrical and temperature characteristics and to ensure the maximum efficiency of power generation. The simulation results of the $I-V$ and $P-V$ characteristic curves of the PV cells show the linear characteristics of the cells' operation, which reduces the instability and complexity of the PV system. Once the working point of the circuit is adjusted to the MPP, the PV cell always operates at the MPP owing to the strict linear relationship between the PV cell and the PV sensor. Similarly to other tracking algorithms, it realizes the automatic tracking of the PV cells to obtain the MPP for enhancing the efficiency of PV cells.

\section{Acknowledgments}

This work was supported by the National Key Research and Development Program of China (No. 2017YFC0804704) and Shanghai Polytechnic University Foundation (No. EGD21QD20).

\section{References}

1 K. M. Ravi, N. S. Satya, and V. Ganesh: Inter. J. Ambient Energy 10 (2020) 1192. https://doi.org/10.1080/01430 750.2018.1492448

2 E. Koutroulis, N. Sason, and V. Georgiadis: IEEE Trans. Power. Elect. 34 (2019) 8634. https://doi.org/10.1109/ TPEL.2018.2883942

3 M. Dhimish: IEEE Trans. Elect. Devi. 66 (2019) 1132. https://doi.org/10.1109/TED.2019.2894009

4 N. Prabaharan, P. E. Campana, A. R. Jerin, and K. Palanisamy: Energy Procedia 159 (2019) 521. https://doi. org/10.1016/j.egypro.2018.12.005

5 H. Chaieb and A. Sakly: Solar Energy 159 (2018) 291. https://doi.org/10.1016/j.solener.2017.11.001 
6 X. F. Shi and S. G. Mu: J. Yuxi. Teach. College 33 (2017) 62. https://doi.org/10.3969/j.issn.10099506.2017.08.010

7 A. Bhattacharjee, H. Samanta, N. Banerjee, and H. Saha: Energy Convers. Manage. 171 (2018) 1449. https:// doi.org/10.1016/j.enconman.2018.06.088

8 Q. Zhu, X. Zhang, and C. Liu: Acta Energiae Solaris Sinica 37 (2016) 1379. https://caod.oriprobe.com/ articles/48869439/IMPROVED PARTICLE SWARM OPTIMIZATION MPPT ALGORITH.htm\#

9 Q. M. Fan, F. Yan, C.F. Zhang, K. Chen, and Y. Q. Zou: Acta Energiae Solaris Sinica 38 (2017) 2151. http://d. wanfangdata.com.cn/periodical/tynxb201708018

10 B. Bendib, H. Belmili, and F. Krim: Renew. Sustain. Energy Rev. 45 (2015) 637. https://doi.org/10.1016/j. rser.2015.02.009

11 A. S. Benyoucef, A. Chouder, K. Kara, S. Silvestre, and O. Aitsahed: Appl. Soft. Comp. 32 (2015) 38. https:// doi.org/10.1016/j.asoc.2015.03.047

12 Y. M. Li and Y. Sui: Chin. J. Power. Sour. 39 (2015) 1416. https://doi.org/10.3969/j.issn.1002-087X.2015.07.021

13 F. Xu: Chin. J. Power. Sour. 38 (2014) 92. https://doi.org/10.3969/j.issn.1002-087X.2014.01.028

14 J. Y. Gu and G. C. Chen: Proc. Chin. Soc. Elect. Eng. 32 (2012) 149. https://doi.org/10.13334/j.0258-8013. pcsee.2012.27.020

15 C. Meng, M. Zhao, and W. J. Zhou: Comput. Simulat. 36 (2019) 128. https://doi.org/

16 L. J. Zhang, S. S. Yu, T. Fernando, H. H. C. Iu, and K. P. Wong: J. Modern Power Syst. Clean. Energy 7 (2019) 357. https://doi.org/10.1007/s40565-018-0440-2

\section{About the Authors}

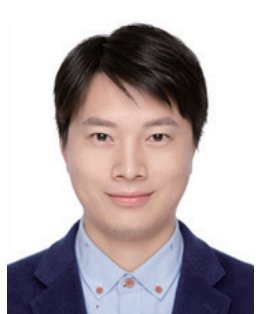

Fujian Zhang received his B.S. degree in electrical engineering and automation from China University of Mining and Technology and his M.S. degree in mechanical design and theory from Shanghai Branch of General Coal Research Institute in 2004 and 2007, respectively. Now he is working in the College of International Vocational Education, Shanghai Polytechnic University. His research interest lies in the key technologies of electric vehicles and vehicle network communication. (fjzhang@sspu.edu.cn)

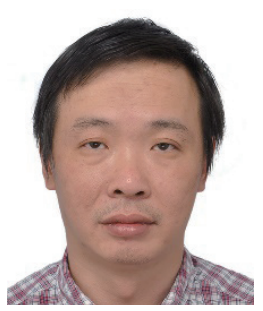

Weidong Ye received his B.S. degree in mechatronics from Shanghai Polytechnic University and his M.S. degree in software engineering from Fudan University. Now he works in Shanghai Polytechnic University. His research direction is in the key technology of industrial engineering and satellite power ground data acquisition and control. (wdye@sspu.edu.cn)



Guoping Lei received his B.S. degree in School of Electronic and Information Engineering from Chongqing Three Gorges University and his M.S. degree in School of Communication and Information Engineering from Chongqing University of Posts and Telecommunications in 2006 and 2009, respectively. Now he is working in Chongqing Three Gorges University, where he is currently a professor. His research interest lies in wireless communication. (187044145@qq.com) 


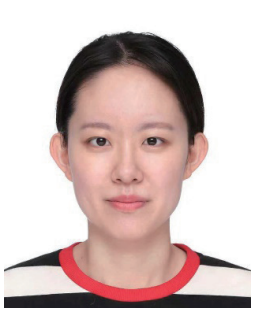

Yingying Liu graduated from Shanghai Dianji University with a major in electrical engineering and from Northeast Petroleum University with a bachelor's degree in electronic information engineering. Now she works at Shanghai Polytechnic University. Her research direction is battery capacity research. (yyliu@sspu.edu.cn)

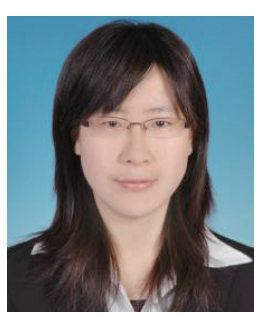

Xian Wang received her B.S. and M.S. degrees from East China University of Science and Technology in 2008 and 2011 in China, respectively. Now she works as a laboratory technician at Shanghai Polytechnic University. Her research areas are about the channel estimation of communication systems and signal processing. (wangxian@sspu.edu.cn)

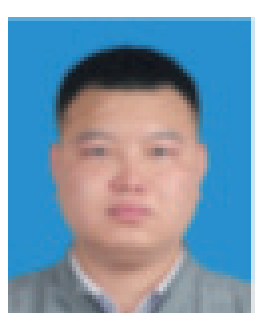

Chao He received his B.S. and M.S. degrees from Chongqing Three Gorges University in China in 2014 and 2017, respectively. Now, he is currently pursuing his Ph.D. degree from School of Communication and Information Engineering, Chongqing University of Posts and Telecommunications. His research interests include MEC, VNE, and FiWi broadband access network. (d170101004@stu.cqupt.edu.cn) 